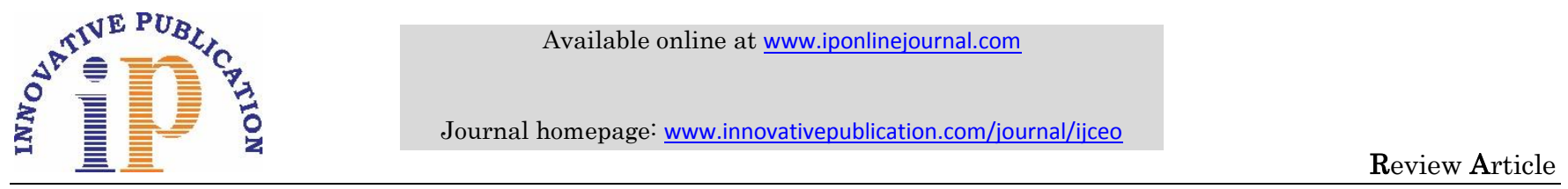

\title{
Ocular manifestations in subacute sclerosing panencephalitis
}

\author{
Yamini Sahu ${ }^{1}$, Niharika Chaudhary ${ }^{2 *}$, Priyanka Singh ${ }^{3}$, Ritika Aggarwal ${ }^{4}$ \\ ${ }^{1}$ Senior Resident, ${ }^{2}$ Assistant Professor, ${ }^{3}$ Senior Research Associate, ${ }^{4}$ Post Graduate, Dept. of Ophthalmology, Vardhman Mahavir Medical \\ College and Safdarjung Hospital, New Delhi, India
}

\section{Article Info}

Received: $12^{\text {th }}$ March, 2019

Accepted: $26^{\text {th }}$ April, 2019

Published Online: $9^{\text {th }}$ September, 2019

Keywords: SSPE- Subacute sclerosing panencephalitis.

\begin{abstract}
Subacute sclerosing panencephalitis is a neurological disorder that leads to progressive neuronal damage caused by persistent measles virus. The usual age of onset of the disease is in childhood between the age of 10 to 14 years. Ocular manifestations are seen in 10 to $50 \%$ of the patients of SSPE. Common ocular findings include optic neuritis, papilledema, papillitis, optic atrophy, macular chorioretinitis, cortical blindness. Ophthalmic findings may occur along with or may sometimes precede the neurological involvement by few years. There is higher incidence in rural population, children with lower birth order, having 2 or more siblings. SSPE is twice as common in boys as in girls. Initial presentation starts as mild behavioral changes, progressing to specific motor and neurological disturbances in the form of myoclonic jerks, motor disturbances leading to involuntary muscle contractions, gait abnormalities, speech changes, pyramidal and extrapyramidal signs, amnesia, generalized tonic clonic seizures and partial seizures. Macular retinochoroiditis is the most common ocular finding in SSPE. The diagnosis is based upon characteristic clinical manifestations, the presence of characteristic periodic slow wave complexes in EEG, and presence of increased antibody titre against measles virus in the plasma and cerebrospinal fluid (three out of five criteria given by Dyken are fulfilled). Treatment for SSPE is still undetermined. Various drug combination therapies have been used for the treatment of SSPE. Isoprinosine was the first drug reported to be effective against SSPE due to its immunomodulatory effects. Alpha interferon is also used for the management of SSPE. Studies suggest that even beta interferon can be used as a management option. Ribavirin, an antiviral drug, is effective against many RNA viruses.
\end{abstract}

\section{Introduction}

Subacute sclerosing panencephalitis is a neurological disorder that leads to progressive neuronal damage caused by persistence of measles virus. The term was first used by Greenfield to describe a condition involving both the grey and white matter of the brain due to persistent viral infection. ${ }^{1}$ In 1933 Dawson described a case with mental retardation and abnormal jerky limb movements in a child with involvement of grey matter. ${ }^{2}$ He suggested a viral etiology for the same. The disease is characterized by behavioral changes usually manifested as worsening school performance usually followed by myoclonic jerks, paresis, dyspraxia, progressive mental and motor deterioration, memory impairment, language difficulties, blindness and eventually coma and death.

The usual age of onset of the disease is in childhood. The child has a history of measles usually before the age of 2 years. The virus has a latent period of 5 to 8 years so the child becomes symptomatic at around 10 to 14 years of age but the latent period may range from 3 months to 18 years. The disease is invariably fatal with death occurring within 1 to 3 years of onset of symptoms. Ocular manifestations are seen in 10 to $50 \%$ of the patients of SSPE. ${ }^{3}$ Common ocular findings include optic neuritis, ${ }^{4}$ papilledema, papillitis, optic atrophy, macular chorioretinitis, ${ }^{5-7}$ cortical blindness. ${ }^{8}$ Ophthalmic findings may occur along with or may sometimes precede the neurological involvement by few years. Hence ophthalmic manifestations might be the presenting feature of a case of SSPE. Therefore it is of utmost importance to know the ophthalmic manifestations so as to raise a suspicion of SSPE aiding in early diagnosis and management.

\section{Epidemiology}

SSPE is usually a problem remaining in developing countries with very few cases seen in the western countries. The incidence has declined drastically after the introduction of measles vaccine. If the disease occurs in prior vaccinated subjects then there is a possibility of contacting the infection before vaccination that is before the age of one year. The attenuated vaccine virus has not shown to be the cause of sporadic cases of SSPE. India has an average incidence of 21 per million ${ }^{9}$ as compared to 2.4 per million population in Middle East.

*Corresponding Author: Niharika Chaudhary, Assistant Professor, Dept. of Ophthalmology, Vardhman Mahavir Medical College and Safdarjung Hospital, New Delhi, India

Email: niharikachaudhari7@gmail.com

http://doi.org/10.18231/j.ijceo.2019.065 
SSPE is a disease of the childhood occurring at around 6 years of age with a history of measles around 2 years of age. Early infection with measles (less than 1 year of age) poses a greater threat of SSPE than a relatively late infection at around 5 years of age. There is higher incidence in rural population, children with lower birth order, having 2 or more siblings, living in crowded unhygienic environment. SSPE is twice as common in boys as in girls. ${ }^{10}$ If the child gets exposed to other viral infection like Ebstein Barr virus simultaneously then this may modify the signs and symptoms of acute infection of measles.

\section{Clinical Features \& General Features}

The usual age of presentation is $8-10$ years. Initially there might be mild behavioral changes in the form of deteriorating school performance noticed by teachers without any specific neurological sign. This progresses to specific motor and neurological disturbances in the form of myoclonic jerks, motor disturbances leading to involuntary muscle contractions, gait abnormalities, speech changes, pyramidal and extrapyramidal signs, amnesia, generalized tonic clonic seizures and partial seizures. ${ }^{17,18}$ Myoclonic jerks start with involvement of the head and then progressing to trunk and limbs. They disappear during sleep and increased on excitement. EEG shows characteristic periodic slow wave pattern.

Fulminant course of SSPE is defined as neurological disability index of 66 in first 3 months or death within 6 months of SSPE onset. Early measles virus infection (before 1 year), trauma and high virulence of virus can lead to a fulminant course.

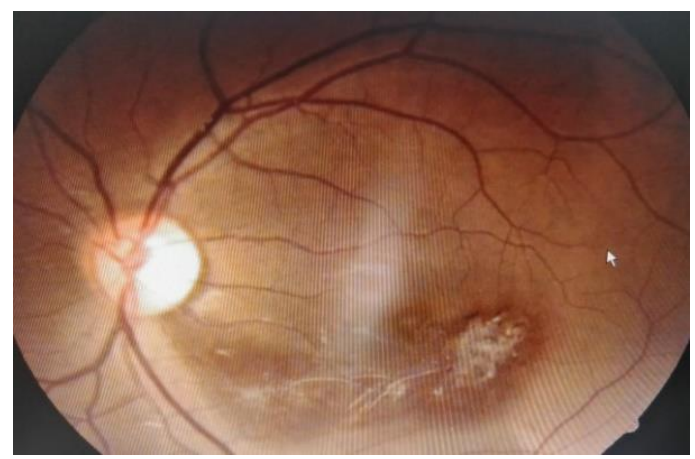

Fig. 1: Healed retinochoroidal macular scar.

\section{Ophthalmic Features}

Ocular manifestations are seen in 10 to $50 \%$ of the patients. Although the visual symptoms occur usually in stage 3 of SSPE but it may also be precede the neurological symptoms by several years causing the ocular symptoms to be the presenting feature of SSPE. Most commonly optic nerve is involved and the most common fundus finding is macular retinitis.

Sometimes the ocular manifestations suggest a more diffuse neurological etiology and might warrant neurological investigations. These manifestations include cortical blindness, visual field abnormalities without any ophthalmoscopic findings, amaurosis fugax, bilateral disc oedema or papillitis, optic atrophy or temporal pallor of disc, nystagmus, supranuclear gaze palsies and ptosis. ${ }^{10}$

Opthalmoscopic findings in SSPE which suggest an ocular problem are pigment epithelial disturbances in macula, macular oedema, macular hemorrhage, retinochoroiditis, gliotic scarring of macula, internal limiting membrane contracture leading to macular hole, drusens and serous detachment of macula. ${ }^{5,7}$

Macular retinochoroiditis is the most common ophthalmoscopic finding in SSPE. ${ }^{5}$ Measles virus inclusions can be easily demonstrated in the form of microtubular and intranuclear inclusions in nuclear layers of retina in patients of retinochoroiditis. ${ }^{11}$ The macular abnormalities begin in the retinal pigment epithelium (manifested as granular appearance) and neuroepithelium (manifested as hemorrhage or edema) with limited choroidal involvement (usually only choriocapillaries). Spread to vitreous cavity is minimal in the form of slight preretinal haze. There are no satellite lesions. Retinal vessel involvement is rare with only mild vessel obscuration at the site of scar. These features help in distinguishing SSPE from toxoplasmic chorioretinitis.

With the disease progression the retinitis either subsides or becomes more severe ultimately leading to a gliotic retinal scar with internal limiting membrane contracture. This may lead to a macular hole formation.

Fluorescein angiography shows retinal vessel capillary occlusion near macula with limited involvement of choroid. Macular pigmentary changes in SSPE are due to involvement of retinal pigment epithelium. Hereditary retinal neuroepithelial degenerations like vitelliform dystrophy of fovea might be a differential.

\section{Differential Diagnosis of Macular Lesion}

Following diseases of macula might mimic lesions seen in SSPE

\begin{tabular}{|l|ll|}
\hline $\begin{array}{l}\text { Hereditary degenerative } \\
\text { diseases of retinal } \\
\text { neuroepithelium }\end{array}$ & $\begin{array}{l}\text { 2. } \\
\text { 3. }\end{array}$ & $\begin{array}{l}\text { Stargardt's disease } \\
\text { Central retinitis pigmentosa } \\
\text { Dominant progressive foveal } \\
\text { dystrophy }\end{array}$ \\
\hline $\begin{array}{l}\text { Hereditary degenerative } \\
\text { diseases of retinal } \\
\text { pigment epithelium }\end{array}$ & Vitelliform dystrophy of the fovea \\
\hline Inflammatory diseases & 1. & $\begin{array}{l}\text { Toxoplasma exudative } \\
\text { retinochoroiditis } \\
\text { epitheliopathy } \\
\text { Cytomegalic inclusion } \\
\text { disease retinitis }\end{array}$ \\
& $\begin{array}{l}\text { 3. } \\
\text { Bechet's disease } \\
\text { Candida retino-choroiditis } \\
\text { Acute posterior multifocal } \\
\text { placoid pigment } \\
\text { epitheliopathy }\end{array}$ \\
\hline $\begin{array}{l}\text { Heredo-degenerations of } \\
\text { Bruch's membrane }\end{array}$ & $\begin{array}{l}\text { Post traumatic macular hole } \\
\text { 2. }\end{array}$ & $\begin{array}{l}\text { Dominant drusen } \\
\text { Pseudo inflammatory foveal } \\
\text { dystrophy }\end{array}$ \\
\hline $\begin{array}{l}\text { Disease affecting } \\
\text { choriocapillaris }\end{array}$ & Central serous choroidopathy \\
\hline
\end{tabular}




\section{Diagnosis of SSPE}

The diagnosis of SSPE is made using the Dyken criteria which needs fulfillment of atleast three out of five criteria.

DYKEN Criteria: three out of five criteria should be fulfilled.

\begin{tabular}{|l|l|}
\hline Clinical & $\begin{array}{l}\text { Progressive, subacute metal } \\
\text { deterioration with typical signs like } \\
\text { myoclonus }\end{array}$ \\
\hline EEG & $\begin{array}{l}\text { Periodic, stereotyped, high voltage } \\
\text { discharges }\end{array}$ \\
\hline $\begin{array}{l}\text { Cerebrospinal } \\
\text { Fluid }\end{array}$ & $\begin{array}{l}\text { Raised gammaglobulin or oligoclonal } \\
\text { pattern }\end{array}$ \\
\hline $\begin{array}{l}\text { Measles } \\
\text { Antibodies }\end{array}$ & $\begin{array}{l}\text { Raised titre in serum }(\geq 1: 256) \text { and/or } \\
\text { cerebrospinal fluid }(\geq 1: 4)\end{array}$ \\
\hline Brain Biopsy & Suggestive of panencephalitis \\
\hline
\end{tabular}

\section{Management}

Various drug combination therapies have been used for the treatment of SSPE. Isoprinosine was the first drug reported to be effective against SSPE due to its immunomodulatory effects. ${ }^{12,13}$ Alpha interferon is also used for the management of SSPE. ${ }^{14}$ It is given via intraventricular route. Some studies suggest that even beta interferon can be used as a management option. Ribavirin, an antiviral drug effective against many RNA viruses is also effective against measles. ${ }^{15}$ Intraventricular Ribavarin has shown to reach a concentration which could stop the SSPE virus replication. ${ }^{16}$ Usually combination therapy is utilized for the management of SSPE.A combination of intraventricular alpha interferon with oral Isoprinosine is currently considered the most effective.

\section{Source of Funding: None.}

Conflict of Interest: None.

\section{References}

1. Greenfield JG. Encephalitis and encephalomyelitis in England and Wales during last decade. Brain. 1950;73:141-66.

2. Dawson JR. Cellular inclusions in cerebral lesions of lethargic encephalitis. Am J Pathol. 1933;9:7-16.

3. Garg RK. Subacute sclerosing panencephalitis. Postgrad Med J. 2002;78:63-70.

4. Oray M, Tuncer S, Kir N, Karacorlu M, Tugal -Tutkun I. Optic neuritis and rapidly progressive necrotizing retinitis as the initial signs of subacute sclerosing panencephalitis: A case report with clinical and histopathologic findings. Int Ophthalmol. 2014;34:983-7.

5. Caruso JM, Robbins-Tien D, Brown WD, Antony JH, Gascon GG. Atypical chorioretinitis as an early presentation of subacute sclerosing panencephalitis. J Pediatr Ophthalmol Strabismus. 2000;37:119-22.

6. Jeevagan V, Dissanayake A. Chorioretinitis: A potential clue to the early diagnosis of subacute sclerosing panencephalitis. Pract Neurol. 2017;17:293-96.

7. Chawla A, Jain S. Subacute sclerosing panencephalitis masquerading as toxoplasmosis chorioretinitis. Can J Ophthalmol. 2012;47:e1-2.
8. Kabra SK, Bagga A, Shankar V. Subacute sclerosing panencephalitis presenting as cortical blindness. Trop Doct. 1992;22:94-5.

9. Saha V, John TJ, Mukundan P. High incidence of subacute sclerosing pancephalitis in South India. Epidemiol Infect. 1990;104:151-6.

10. Yilmaz D, Aydin OF, Senbil N, Yuksel D. Subacute sclerosing panencephalitis: Is there something different in the younger children? Brain Dev. 2006;28:649-652.

11. Park DW, Boldt HC, Massicotte SJ, Akang EE, Roos KL, Bodnar A, et al. Subacute sclerosing panencephalitis manifesting as viral retinitis: clinical and histopathologic findings. Am J Ophthalmol. 1997;123:533-4.

12. Streletz LJ, Cracco J. The effect of isoprinosine in subacute sclerosing panencephalitis (SSPE). Ann Neurol. 1977;1:183-4.

13. Huttenlocher PR, Mattson RH. Isoprinosine in subacute sclerosing panencephalitis. Neurol. 1979;29:763-771.

14. Yoshioka H, Nishimura O, Nakagawa M, Ochi M, Takeuchi Y, Tominaga M, et al. Administration of human leukocyte interferon to patients with subacute sclerosing panencephalitis. Brain Dev. 1989;11:302-7.

15. Tomoda A, Nomura K, Shiraishi S, Hamada A, Ohmura T, Hosoya M, et al. Trial of intraventricular ribavirin therapy for subacute sclerosing panencephalitis in Japan. Brain Dev. 2003;25:514-7.

16. Hosoya M, Mori S, Tomoda A, Mori K, Sawaishi Y, Kimura $\mathrm{H}$, et al. Pharmacokinetics and effects of ribavirin following intraventricular administration for treatment of subacute sclerosing panencephalitis. Antimicrob Agents Chemother. 2004;48:4631-5.

17. Woveland PT, Johnson KP. Subaute sclerosing panencephalitis and other paramyxovirus infections. In: Mckendall RR, ed. Handbook of clinical neurology. Vol 12 (56). Virus diseases. Amsterdam: North Holland Publishing Company, 1989:417-37.

18. Aha V, John TJ, Mukundan P. High incidence of subacute sclerosing panencephalitis in South India. Epidemiol Infect. 1990; 104:151-6.

How to cite this article: Sahu Y, Chaudhary N, Singh P, Aggarwal R. Ocular manifestations in subacute sclerosing panencephalitis. Indian $J$ Clin Exp Ophthalmol 2019;5(3):272-4. 